\title{
Report of the Sensuous Analysis of the Concept of Tahara's I Function
}

\author{
Horiuchi Daiki
}

November 17, 2019

\begin{abstract}
\end{abstract}
I felt that it is interesting.

\section{Explanation}

In order to prove the Quranic correctness, my classmate Tahara Hiroki defined Tahara's $I$ function as follows:

$$
I=\sum i\left(i: 2^{[\text {Q.S. }]} \times 2^{[\text {T.P. }]} \longrightarrow 2^{[\text {T.P. }]} \wedge i: \text { meaningful }\right)
$$

and proved that Quran is correct if and only if Tahara's $I$ function exists uniquely. Reading references, I felt that that is interesting.

\section{References}

[1] Hiroki Tahara. The Mathematical Expressions of Quranic Exegeses and the Mathematical Definition of the Quranic Correctness. OSF Preprints, 6dsxb, 2019.

[2] Hiroki Tahara. Methodology to Prove the Quranic Correctness. International Journal of Humanities and Social Science Invention, 2019, 8.(10:1): 01-02.

[3] Hiroki Tahara. A Brainstorming of the Quranic Studies Inspired by the Evaluation of Coefficients of Polynomials. OSF Preprints, 6n9p3, 2019.

[4] Hiroki Tahara. Inspiration about the Importance of Semantics to Prove the Quranic Correctness. OSF Preprints, 4rphv, 2019.

[5] 田原裕基. 規範倫理学における公理について. viXra preprint, 1908.0553, 2019.

[6] 田原裕基. 1 期間 2 項モデルを活用した失業保険の価格決定. viXra preprint, 1909.0302, 2019. 
[7] 田原裕基. 時制概念と位相幾何学に関する閃き. OSF Preprints, ed4zj, 2019.

[8] Daiki Horiuchi, Taiga Imanishi, Kento Nishi, Hiroki Tahara. An Emotional Analysis of the Concept of Tahara I Function. OSF Preprints, 9thk3, 2019.

[9] Daiki Horiuchi, Taiga Imanishi, Kento Nishi. An Emotional Analysis of the Concept of Tahara I Function II. OSF Preprints, vpfma, 2019. 